ORIGINAL ARTICLE

\title{
Use of medical emergency team (MET) responses to detect medical errors
}

\author{
R S Braithwaite, M A DeVita, R Mahidhara, R L Simmons, S Stuart, M Foraida, and members of the \\ Medical Emergency Response Improvement Team (MERIT)*
}

See end of article for authors' affiliations

Correspondence to:

$\operatorname{Dr} M A$ DeVita, University

of Pittsburgh Medical

Centre Presbyterian

Hospital, 200 Lothrop

Street, Pittsburgh, PA

15213, USA; devitam@

msx.upmc.edu

Accepted for publication 9 May 2004
Background: No previous studies have investigated whether medical emergency team (MET) responses can be used to detect medical errors.

Objectives: To determine whether review of MET responses can be used as a surveillance method for detecting medical errors.

Methods : Charts of all patients receiving MET responses during an 8 month period were reviewed by a hospital based Quality Improvement Committee to establish if the clinical deterioration that prompted the MET response was associated with a medical error (defined as an adverse event that was preventable with the current state of medical knowledge). Medical errors were categorized as diagnostic, treatment, or preventive errors using a descriptive typology based on previous published reports.

Results: Three hundred and sixty four consecutive MET responses underwent chart review and 114 $(31.3 \%)$ were associated with medical errors: 77 (67.5\%) were categorized as diagnostic errors, 68 $(59.6 \%)$ as treatment errors, and $30(26.3 \%)$ as prevention errors. Eighteen separate hospital care processes were identified and modified as a result of this review, 10 of which involved standardization. Conclusions: MET review may be used for surveillance to detect medical errors and to identify and modify processes of care that underlie those errors.
$\mathrm{R}$ ecent reports have estimated that between 44000 and 98000 preventable deaths occur annually in the US because of medical errors. ${ }^{1-11}$ There is a consensus among safety researchers that most medical errors are not the sole result of individual caregivers but, rather, are induced by latent failures in organizational structures or processes. ${ }^{12-17}$ For this reason, many have proposed that analyzing the root causes of medical errors is of paramount importance for reducing their future incidence. ${ }^{12-17}$ However, in order to analyze medical errors it is first necessary to identify them, and little is known about the most effective surveillance methods for their detection.

Medical errors that are particularly harmful may lead to life threatening clinical deterioration or death. At our institution episodes of life threatening clinical deterioration or sudden death trigger a response by a medical emergency team (MET), a recently developed process of care in which groups of healthcare professionals are assembled to respond more effectively to inpatient crises. ${ }^{18-26}$ For this reason, we hypothesized that reviewing the episodes of care surrounding MET responses may be a fruitful case finding technique for detecting those medical errors that are particularly harmful. We therefore introduced a quality improvement initiative that mandated a chart review after every MET response. Our aim was to detect medical errors that were particularly harmful and that would not have been detected by other means. In this report we describe how surveillance of MET responses may be used to detect harmful medical errors, and how root cause analysis of the care processes underlying these errors may be used to improve patient safety.

\section{METHODS}

The University of Pittsburgh Medical Center (UPMC) Presbyterian Hospital uses an MET to respond to any medical crisis. It can be activated by any hospital staff member who witnesses grave clinical deterioration. It is described in more detail in our accompanying paper ${ }^{27}$ and is outlined in table 1.
Our institution comprises 567 licensed beds in three contiguous hospitals, outpatient clinics, a medical school, a rehabilitation facility, and a skilled nursing facility, all connected by bridges and tunnels. The same MET system is used for the entire complex but, because of the size of the facility, different personnel comprise teams in three separate geographical zones.

\section{Chart review}

Charts of all patients for which the emergency response team was activated during an 8 month period (May-December 2000) were reviewed by a hospital based Quality Improvement Committee within 1 month of the response to establish if the clinical deterioration that prompted the MET response was associated with a medical error. These reviews were usually retrospective and occurred after patients had left the hospital. However, if committee members were notified through informal channels that a medical error may have led to an MET response or if the patient had a particularly long stay in hospital, the review may have occurred while the patient was still in the hospital. During the 8 month period that is the subject of the present report, the committee operated with the imperative of reviewing every MET response regardless of time requirements and successfully reviewed all cases.

Information from the medical records of patients requiring an MET response was abstracted by a team of surgical residents using our institution's electronic medical record system. Each case was assigned to a particular resident and each abstraction took approximately half an hour. During abstraction emphasis was placed on recording a minute by minute sequence of events prior to the MET response including clinical signs and symptoms, tests ordered, personnel

\footnotetext{
* See end of article for list of members of Medical Emergency Response
} Improvement Team. 
Table 1 Personnel staffing medical emergency team (MET) responses

\begin{tabular}{|c|c|c|}
\hline Personnel & Role & Objective \\
\hline ICU physician & Team leader & Direct ACLS team efforts, medical decision making \\
\hline ICU nurse & Run medication/equipment cart & $\begin{array}{l}\text { Prepare medications, equipment, defibrillator for } \\
\text { delivery to patient }\end{array}$ \\
\hline ICU nurse & Recorder & $\begin{array}{l}\text { Coordinate data flow: record events, labs sent, } \\
\text { obtain results, other data as required }\end{array}$ \\
\hline Floor nurse & Bedside nursing & $\begin{array}{l}\text { Deliver medications, obtain vital signs, verify IV } \\
\text { function }\end{array}$ \\
\hline $\begin{array}{l}\text { Anesthesia or } \\
\text { critical care }\end{array}$ & Airway manager & Assure oxygenation and ventilation \\
\hline Respiratory care & Airway assistant & Oxygen supply, suction, respiratory equipment \\
\hline Physician & Chest compressions & Assess circulation, deliver chest compressions \\
\hline Physician & Procedure physician & $\begin{array}{l}\text { Perform required procedures: obtain arterial blood } \\
\text { for analysis, thoracostomy, central venous access }\end{array}$ \\
\hline
\end{tabular}

directly involved in the care, and personnel consulted. In addition to this timeline, they also abstracted a vignette of the patient's initial presentation to the hospital and a description of the patient's outcome following the MET response. An example is shown in box 1. Because this effort was a quality improvement initiative, review by our Institutional Review Board was not required.

\section{Quality Improvement Committee}

The abstracted information was reviewed by members of the Quality Improvement Committee and each review took approximately 10 minutes.

\section{Membership}

Membership of the committee included attending physicians in the surgery, critical care, and general internal medicine departments, trainees in the surgical residency program, and nurse administrators. Attendees varied somewhat from session to session, but almost always included at least one surgeon and one critical care physician, surgical trainees, and a senior nurse administrator. The chair of the committee was also the medical director of our institution. The committee made all decisions by consensus during working meetings which were held three times per week. A protocol was used to guide the identification and categorization of medical errors. In reviewing the chart, the committee determined whether there was an associated adverse event and, if so, whether that adverse event was preventable and the result of a medical error.

\section{Definitions}

A medical error was defined as "an adverse event that was preventable with the current state of medical knowledge." ${ }^{1-3}$ An adverse event was defined as "an injury caused by medical management rather than by the underlying disease or condition of the patient" (e.g. sepsis). ${ }^{1-3}$ The committee operated in accordance with two main premises: (1) a substantial proportion of preventable adverse events do not result from active errors performed by particular individuals, but rather from latent errors attributable to the underlying process of care or other system characteristics (for example, respiratory arrest during patient controlled analgesia occurred not because of any particular error but because a number of pharmacy, nursing and educational processes enabled errors to occur); and (2) even when active errors are important in the etiology of adverse events, they are often induced or permitted by latent errors (for example, the wrong medication was given to a patient and this occurred in part because similarly appearing medication canisters were stocked on the same supply shelf).
Errors were categorized by a descriptive and non-mutually descriptive typology based on previous published reports. ${ }^{1-3}$ Diagnostic errors included incorrect or delayed diagnoses, failure to employ indicated tests, or failure to act on results of monitoring or testing. Treatment errors included errors in the performance of an operation, treatment, or test; errors in the administration of a treatment; errors in the dose or method of using a drug; and inappropriate (not indicated) care. Preventive errors included failure to provide prophylactic treatment and inadequate monitoring or follow up of treatment. Medication errors and errors due to procedures were considered subgroups of treatment errors.

\section{Assessment}

With the intent of characterizing latent errors and reducing their risk of reoccurrence, the committee deliberated on whether there were identifiable root causes and whether particular processes of care may have contributed. If the committee determined that (1) processes of care contributed to the adverse event, (2) these processes could be modified, and (3) their modification could reduce the likelihood of similar adverse events in the future, then a hospital task force was created and delegated to the appropriate hospital department to review and improve the process. This committee had the authority to convene task forces within any hospital department with the aim of improving quality of care.

\section{RESULTS}

Three hundred and sixty four MET responses (18.4 per 1000 hospital admissions) occurred during the 8 month period of review for medical errors, and all cases were reviewed by the Quality Improvement Committee. The MET responses generally occurred in response to acute and serious deteriorations in clinical status; $30 \%$ of patients were in cardiopulmonary arrest and $25 \%$ died on the day of the event.

\section{Medical errors}

A review of the episodes of care preceding MET responses showed that $114(31.4 \%)$ of the deteriorations were attributable to one or more medical errors. Seventy seven (67.5\%) were categorized as diagnostic errors (errors that resulted from improper or delayed diagnosis, failure to employ indicated tests, or failure to act on the results of monitoring or testing), $68(59.6 \%)$ were categorized as treatment errors (errors involving an operation, procedure, test, or drug; 57 of these involved medications), and 30 (26.3\%) were categorized as prevention errors (errors resulting from a failure to provide prophylactic treatment such as not using DVT prophylaxis for immobile patients, or inadequate surveillance for at risk events such as not keeping a patient with rapid 


\section{Box 1 Example of chart review}

The following information was abstracted and presented to the Quality Improvement Committee. In this particular case, the committee determined that there were associated adverse events (intubation, iatrogenic peritonitis, prolonged hospitalization). In addition, there were the following associated medical errors: delay in transfer to the intensive care unit (a preventive error), delay in performing thoracotomy (a diagnostic error), and iatrogenic peritonitis due to percutaneous endoscopic gastrostomy tube placement (a treatment error).

Vignette

A 78 year old female admitted from outside hospital with diagnosis of community acquired pneumonia, failing to improve on vancomycin and piperacillin/tazobactam. Past medical history was unremarkable.

\section{Timeline}

4/17 AM: Arrived on general medicine floor. History and physical examination revealed patient to be "acutely ill and tachypnic, and with cold extremities". Vital signs included a respiratory rate of 24 and were otherwise unremarkable. Arterial oxygen saturation was $91 \%$ on 6 liters/minute oxygen by nasal cannula. Other diagnostic data were notable for chest radiography showing right lung "white out" and a peripheral white blood cell count of 22000 .

4/17 10.53: Arterial blood gas obtained on 6 liters/minute oxygen showed $\mathrm{pH} 7.27$, oxygen pressure $64 \mathrm{~mm} \mathrm{Hg}$, and carbon dioxide pressure $50 \mathrm{~mm} \mathrm{Hg}$. Patient was started on bilevel positive airway pressure (BIPAP).

4/17 15.30: Patient "restless but responsive to vocal commands". Blood pressure decreased to $90 / 60$. Oxygen saturation decreased to $82 \%$, after which oxygen flow rate was increased from 6 liters/minute to 15 liters/minute.

4/17 16.16: Repeat arterial blood gas revealed $\mathrm{pH} 7.27$, oxygen pressure $80 \mathrm{~mm} \mathrm{Hg}$, and carbon dioxide pressure $50 \mathrm{~mm} \mathrm{Hg}$ (now on 15 liters/minute oxygen).

4/17 20.00: Respiratory rate increased to 34; blood pressure and arterial oxygen saturation stable.

4/17 20.30: Repeat arterial blood gas showed pH 7.21, oxygen pressure $90 \mathrm{~mm} \mathrm{Hg}$, carbon dioxide pressure $62 \mathrm{~mm} \mathrm{Hg}$.

4/17 21.42: Decreased mental status noted. MET response called.

\section{Outcome of MET response}

STAT transfer to medical intensive care unit and urgent intubation. Thoracoscopy was performed on 4/19 (2 days after arrival) which showed an empyema. Patient survived acute episode and then had protracted hospital stay lasting 62 days. Contributing co-morbidities included development of peritonitis after a percutaneous endoscopic gastrostomy tube became dislodged and discharged contents into peritoneum.

diuresis on telemetric monitoring to detect hypokalemiarelated arrhythmias). Of the diagnostic errors, approximately half $(\mathrm{n}=39)$ originated from delays in diagnoses (for example, postponement of computer assisted tomography to rule in pulmonary embolism with consequent delay in anticoagulation treatment), and half $(n=38)$ resulted from incorrect diagnoses (for example, assuming chest pain was from costochondritis rather than pulmonary embolism with consequent failure to give anticoagulation treatment).

\section{Processes of care}

Root cause analysis was an effective means of identifying many processes of care that contributed to these medical errors, and ultimately led to institutional interventions that modified these processes in order to reduce the likelihood of similar errors occurring in the future. Eighteen separate processes of care were identified and separate institutional task forces were convened to improve each process (table 2). The majority of task forces chose to improve care processes by ensuring greater standardization. Ten of the 18 task forces standardized caregiver actions by creating protocols (for example, for administration of IV potassium), five limited the performance of a particular process of care to a specialized and highly trained subgroup (for example, a dedicated team to insert small bore feeding tubes), and two standardized the equipment involved in care processes (for example, ensuring crash carts are uniform throughout the facility). Improvement strategies were not entirely limited to standardization, however. Five task forces implemented a risk stratification protocol to ensure that high risk patients received appropriate surveillance (for example, delineating schedule for tracheostomy surveillance by respiratory therapists). In three cases the task forces created a mechanism for more rapid access to a particular element of care such as the development of a mechanism for obtaining large volumes of unmatched blood. Lastly, in one case, a task force modified an element in the physical plant of the hospital that was unexpectedly found to cause iatrogenic morbidity (falls among the elderly while using automatic doors at the entrance to the hospital).

\section{DISCUSSION}

This is the first published report describing the use of MET responses as a surveillance method for detecting medical errors. We found that approximately one third of the episodes of acute clinical deterioration that prompted MET responses were associated with one or more medical errors. We systematically conducted root cause analyses of these errors and were able to identify and improve numerous processes of care that otherwise would have gone undetected.

Most of the care processes that contributed to medical errors carried the risk of great harm yet were not highly standardized. Lack of standardization of complex and potentially dangerous tasks has been reported as one of the most common human factors contributing to error in both medical and non-medical safety literature. ${ }^{12-18}$ Depending on the particular process, standardization was achieved either by establishing protocols or guidelines for caregiver actions, limiting personnel authorized to perform an action to a select group of highly qualified specialists, or by establishing uniformity among the required equipment.

If the true rate of medical error in our hospital is similar to previous national reports (29-37 per 1000 admissions), ${ }^{1}$ the frequency of MET responses (18.4 per 1000 admissions) and the proportion associated with medical errors (31\%) suggest that MET reviews alone may have detected approximately one fifth of all medical errors in our institution. This method may therefore be more sensitive than other methods that rely on voluntary or mandatory reporting, which may have sensitivities as low as $3.7 \% .^{28}$ Furthermore, the errors identified by MET review were generally serious and life threatening, in contrast with the preponderance of non-life threatening errors that are identified through mandatory surveillance mechanisms such as pharmacy errors. This method may therefore have high specificity for detecting those errors that have the greatest impact on patient morbidity and mortality. Furthermore, we conjecture that errors that are linked to life threatening crises motivate staff to improve the underlying care processes with far more 
Table 2 Root cause analysis of medical errors detected from review of medical emergency team (MET) responses

\begin{tabular}{|c|c|c|}
\hline Error & Root cause & Care process improvement \\
\hline \multicolumn{3}{|l|}{ Treatment errors: } \\
\hline Cardiac arrest from hyperkalemia & $\begin{array}{l}\text { Difficult to distinguish potassium solutions of } \\
\text { different strength }\end{array}$ & $\begin{array}{l}\text { Protocol for administration of IV potassium. High } \\
\text { concentrations limited to pharmacy. }\end{array}$ \\
\hline $\begin{array}{l}\text { Respiratory depression from excessive } \\
\text { narcotic dosing during conscious sedation }\end{array}$ & Inadequate supervision of medical trainees & $\begin{array}{l}\text { Guidelines for the use of conscious sedation on general care } \\
\text { units developed; identification of patients as high risk (i.e. } \\
\text { sleep apnea) }\end{array}$ \\
\hline $\begin{array}{l}\text { Aspiration pneumonia or pneumothorax } \\
\text { after feeding tube insertion }\end{array}$ & Inadequate supervision of medical trainees & Dedicated team to insert small bore feeding tubes. \\
\hline $\begin{array}{l}\text { Respiratory depression from excessive } \\
\text { narcotic dosing with PCA }\end{array}$ & $\begin{array}{l}\text { PCA pumps may be used by non-intended } \\
\text { personnel (family) }\end{array}$ & $\begin{array}{l}\text { Protocol for PCA education laminated on cards and placed } \\
\text { on equipment }\end{array}$ \\
\hline $\begin{array}{l}\text { Respiratory distress from hypoxia during } \\
\text { transport }\end{array}$ & $\begin{array}{l}\text { Oxygen tanks not checked before potentially } \\
\text { long transport excursions }\end{array}$ & Oxygen tank exchange protocol \\
\hline $\begin{array}{l}\text { Pneumothorax and other injuries from } \\
\text { placing central venous catheter }\end{array}$ & $\begin{array}{l}\text { Inadequate supervision of medical trainees, } \\
\text { particularly during offshifts }\end{array}$ & $\begin{array}{l}\text { Certification program for bedside procedures. Supervision } \\
\text { available } 24 / 7\end{array}$ \\
\hline \multicolumn{3}{|l|}{ Diagnostic errors } \\
\hline $\begin{array}{l}\text { Cardiopulmonary arrest, various } \\
\text { etiologies from delays in treatment }\end{array}$ & Ambiguous physician in charge & Objective criteria for MET activation \\
\hline $\begin{array}{l}\text { Cardiopulmonary arrest, various } \\
\text { etiologies from delays in treatment }\end{array}$ & $\begin{array}{l}\text { Difficult to obtain ICU bed when hospital census } \\
\text { is high }\end{array}$ & $\begin{array}{l}\text { New MD position established (Resource Intensivist) } \\
\text { responsible for triage within and among ICUs }\end{array}$ \\
\hline $\begin{array}{l}\text { Delay in first shock during } \\
\text { cardiopulmonary arrest }\end{array}$ & $\begin{array}{l}\text { Crash carts stocked in inconsistent or incomplete } \\
\text { manner }\end{array}$ & Standardized crash carts throughout the facility. \\
\hline $\begin{array}{l}\text { Exsanguination from delay in blood } \\
\text { availability }\end{array}$ & $\begin{array}{l}\text { Blood products difficult to access quickly outside } \\
\text { emergency department }\end{array}$ & $\begin{array}{l}\text { Developed mechanism for obtaining large volumes of } \\
\text { unmatched blood }\end{array}$ \\
\hline $\begin{array}{l}\text { Bradycardia/asystole from delay in } \\
\text { pacemaker placement }\end{array}$ & $\begin{array}{l}\text { Permanent pacemaker placement considered a } \\
\text { low priority consult }\end{array}$ & $\begin{array}{l}\text { Initiated dialogue with cardiology that resulted in more } \\
\text { accurate triaging }\end{array}$ \\
\hline \multicolumn{3}{|l|}{ Prevention errors } \\
\hline $\begin{array}{l}\text { Inadequate surveillance for mucus } \\
\text { plugging and other complications in } \\
\text { tracheostomy patients }\end{array}$ & $\begin{array}{l}\text { Non-surgical floors may be staffed by personnel } \\
\text { with little familiarity with tracheostomy care }\end{array}$ & $\begin{array}{l}\text { Protocol delineating schedule for tracheostomy surveillance } \\
\text { by respiratory therapists }\end{array}$ \\
\hline $\begin{array}{l}\text { Inadequate surveillance for rebound } \\
\text { hypoglycemia following treatment of }\end{array}$ & $\begin{array}{l}\text { Danger of hypoglycemia after IV insulin is } \\
\text { underappreciated by hospital staff }\end{array}$ & $\begin{array}{l}\text { Protocol describing frequency of monitoring after insulin } \\
\text { boluses are administered }\end{array}$ \\
\hline glucose or potassium abnormalities & & \\
\hline $\begin{array}{l}\text { Inadequate surveillance for medical } \\
\text { deterioration in patients receiving } \\
\text { radiology tests }\end{array}$ & $\begin{array}{l}\text { Patients in radiology department not supervised } \\
\text { by medical personnel }\end{array}$ & $\begin{array}{l}\text { Pulse oximetry monitoring during radiology tests/ } \\
\text { procedures with MET activation if alarm }\end{array}$ \\
\hline $\begin{array}{l}\text { Inadequate surveillance for medical } \\
\text { deterioration in patients in transport }\end{array}$ & $\begin{array}{l}\text { Patients in transport not supervised by medical } \\
\text { personnel }\end{array}$ & $\begin{array}{l}\text { Pulse oximetry monitoring during transport with MET } \\
\text { activation if alarm }\end{array}$ \\
\hline $\begin{array}{l}\text { Deaths and colectomies from iatrogenic } \\
C \text { difficile exposure }\end{array}$ & $\begin{array}{l}\text { Excessive broad spectrum antibiotic use; } \\
\text { inadequate infection control }\end{array}$ & C difficile task force and antibiotic management team \\
\hline $\begin{array}{l}\text { Fractures, subdural hematomas from falls } \\
\text { in demented elderly }\end{array}$ & Restraints, no supervision, unpadded environment & Falls task force \\
\hline $\begin{array}{l}\text { Fractures from falls in elderly using } \\
\text { automatic doors }\end{array}$ & $\begin{array}{l}\text { Doors not clearly marked and operate too fast } \\
\text { for elderly patients }\end{array}$ & $\begin{array}{l}\text { Automated messages of door use, reduced speed of } \\
\text { automatic doors }\end{array}$ \\
\hline
\end{tabular}

enthusiasm than errors that are associated with minimal morbidity.

Most error detection methodologies aim to find incident cases of a specific type of error that has already been recognized, such as wrong side surgery. However, we are in the infancy of medical error detection as a field of scientific investigation, and many of the latent errors that contribute to morbidity and mortality may not yet have been identified. Another advantage of using MET response review as a means of error detection is that the investigation is not limited to any specific care process or error type, and hitherto unrecognized errors with high morbidity and mortality impact can be identified. For example, our reviews have uncovered a high incidence of preventable and serious errors stemming from insufficient monitoring of patients with tracheostomies for mucus plugging and other tracheostomy related complications. In addition, our reviews have uncovered a high incidence of dangerous and easily preventable hypoglycemia after hyperkalemic patients have received intravenous insulin. Even though both these types of errors are serious and eminently preventable, they would not have been detected by conventional error finding strategies.

\section{Limitations}

Our report has numerous limitations. Data were recorded over a period of less than 1 year and analyses were based on a relatively small number of MET responses and medical errors. The typology used to categorize the medical errors was rudimentary and was based on categories that were not mutually exclusive. The unblinded nature of the reviews may have resulted in hidden biases-for example, it is possible that our MET responses could have resulted in closer scrutiny of events leading up to a medical crisis and result in a higher likelihood that the reviewers would consider an action (or inaction) to be an error. Despite these limitations, we feel that our results have important implications and may guide quality improvement initiatives at other institutions where MET implementation is being considered.

\section{CONCLUSION}

MET is a recently developed process of care that is designed to ensure effective responses to inpatient crises. We report a new use for this process as a surveillance mechanism for detecting medical errors. Our data suggest that peer review of the care preceding MET responses is an efficient way of detecting errors with a particularly high impact on patient morbidity and mortality, as well as types of errors that have not yet been recognized. We were also able to use this approach to identify and improve many processes of care that contributed to medical errors at our institution. Evaluating the benefit of MET review for identifying and targeting medical errors in other healthcare settings is warranted. 


\section{Key messages}

- Although medical emergency teams (METs) were designed to respond more effectively to inpatient crises, they may also be used to identify medical errors that cause harm.

- Root cause analysis of medical errors may be used to identify the processes of care that are latent factors underlying those errors.

- Hospital processes of care may be modified to reduce the likelihood that similar medical errors will occur in the future.

\section{ACKNOWLEDGEMENTS}

The authors acknowledge the database support provided by Tameria Tomman and Sharmeen Fasihuzzaman.

\section{Authors' affiliations}

M A DeVita, Patient Safety Program, Department of Critical Care Medicine, University of Pittsburgh Medical Center Presbyterian Hospital Pittsburgh, PA, USA

R Mahidhara, R L Simmons, Patient Safety Program, Department of Surgery, University of Pittsburgh Medical Center Presbyterian Hospital, Pittsburgh, PA, USA

R S Braithwaite, Patient Safety Program, Department of Internal Medicine, University of Pittsburgh Medical Center Presbyterian Hospital, Pittsburgh, PA, USA

S Stuart, M Foraida, University of Pittsburgh Medical Center Presbyterian Hospital, Pittsburgh, PA, USA

MERIT Committee: D Annonio RN, N Bircher MD, K Castelnuovo, C Colleen, K Drain, G Gotaskie RN, W Grbach RN, C Griffin RN, L Haas RN, J Hanna RN, C Herisko MSN, RN, M Hudak RN, D Konop RN, J Kowiatek PharmD, P Matthews RN, J McWilliams RN, N Mininni MSN, RN, V Mossesso MD, P Natale RN, P O'Driscoll, J Phillips, C Schollee RN, D Shearn RN, T Smitherman MD, S Svec RN, V Tappe RN, A Towers $M D$, J Turka RN, D Zimmer RN.

\section{REFERENCES}

1 Kohn L, Corrigan J, Donaldson M, eds. To err is human: building a safer health system. Committee on Quality of Health Care in America, Institute of Medicine. Washington, DC: National Academay Press, 2000.

2 Brennan TA, Leape LL, Laird NM, et al. Incidence of adverse events and negligence in hospitalized patients. N Engl J Med 1991;324:370-6.
3 Leape LL, Brennan TA, Laird NM et al. The nature of adverse events in hospitalized patients. N Engl J Med 1991;324:377-84.

4 McDonald CJ, Weiner M, Hui SL. Deaths due to medical errors are exaggerated in Institute of Medicine report. JAMA 2000;284:93-5.

5 Shojania KG, Duncan BW, McDonald KM, et al. Safe but sound: patient safety meets evidence based medicine. JAMA 2002;288:508-13.

6 Rosner F, Berger JT, Kark P, et al. Disclosure and prevention of medical errors. Arch Intern Med 2000;160:2089-92.

7 Rothschild JM, Bates DW, Leape L. Preventable medical injuries in older patients. Arch Intern Med 2000;160:2717-28.

8 Layde PM, Maas LA, Teret SP, et al. Patient safety efforts should focus on medical injuries. JAMA 2002;287:1993-6.

9 McNutt RA, Abrams R, Aron DC, et al. Patients safety efforts should focus on medical errors. JAMA 2002;287:1997-2001.

10 Leape LL, Berwick DN, Bates DW. What practices will most improve safety? Evidence-based medicine meets patient safety. JAMA 2002;288:501-13.

11 Hsai DC. Medicare quality improvement. Bad apples or bad systems? JAMA 2003;289:345-56.

12 Charles V, Taylor-Adams S, Stanhope N. Framework for analysing risk and safety in clinical medicine. BMJ 1998;316:1154-7.

13 Wears RL, Leape LL. Human error in emergency medicine. Ann Emerg Med 1999;34:370-2.

14 Wears RL, Janiak B, Moorhead JC, et al. Human error in medicine: promise and pitfalls, part 2. Ann Emerg Med 2000;36:142-4.

15 Reason JT, Carthey J, deLeval MR. Diagnosing "vulnerable system syndrome:" an essential prerequisite to effective risk management. Qual Health Care 2001; 10(Suppl II):ii21-5

16 Barach P, Small SD. Reporting and preventing medical mishaps: lessons from non-medical near reporting systems. BMJ 2000;320:759-63.

17 Nolan TW. System changes to improve patient safety. BMJ 2000;320:771-3.

18 Spencer FC. Human error in hospitals and industrial accidents: current concepts. J Am Coll Surg 2000;191:410-8.

19 Hodgetts TJ, Kenward G, Vlachonikolis IG, et al. The identification of risk factors for cardiac arrest and formulation of activation criteria to alert a medical emergency team. Resuscitation 2002;54:125-31.

20 Hodgetts TJ, Kenward G, Vlachonikolis IG, et al. Incidence, location and reasons for avoidable in-hospital cardiac arrest in a district general hospital. Resuscitation 2002:54:115-23.

21 Buist MD, Moore GE, Bernard SA, et al. Effects of a medical emergency team on reduction of incidence of and mortality from unexpected cardiac arrest in hospital: preliminary study. BMJ 2002;324:1-6.

22 Bristlow PJ, Hillman KM, Chey T, et al. Rates of in-hospital arrests, deaths and intensive care admissions: the effect of a medical emergency team. Med J Aust $2000 ; 173: 236-40$.

23 Buist MD, Jarmolowski E, Burton PR, et al. Recognising clinical instability in hospital patients before cardiac arrest or unplanned admission to intensive care. MJA 1999;171:22-5.

24 Goldhill DR, Worthington L, Mulcahy A, et al. The patient-at-risk team: identifying and managing seriously ill ward patients. Anesthesia 1999;54:853-60

25 Lee A, Bishop G, Hillman KM, et al. The Medical Emergency Team. Anaesth Intens Care 1995;23:183-6.

26 Daly FFS, Sidney KL, Fatovich DM. The medical emergency team (MET): a model for the district general hospital. Aust NZ J Med 1998;28:795-8.

27 DeVita MA, Braithwaite RS, Mahidhara R, et al. Use of medical emergency team responses to reduce hospital cardiopulmonary arrests. Qual Saf Health Care 2004; 13:251-4.

28 Jha AK, Kuperman GJ, Teich JM, et al. Identifying adverse drug events: development of a computer-based monitor and comparison with chart review and voluntary report. J Am Med Informatics Ass 1998;5:305-13. 